\title{
Accumulative roll bonding of a Mg-based AZ61 alloy
}

\author{
J.A. del Valle, M.T. Pérez-Prado, O.A. Ruano \\ Department of Physical Metallurgy, Centro Nacional de Investigaciones Metalúrgicas (CENIM), \\ CSIC, Avda. Gregorio del Amo, 8, 28040 Madrid, Spain
}

\begin{abstract}
This work aims to investigate whether accumulative roll bonding (ARB) is an effective grain refinement technique for the $\mathrm{Mg}-\mathrm{Al}$ alloy $\mathrm{AZ61}$. Thus, a number of $\mathrm{ARB}$ routes at $300 \mathrm{C}$ and 400 $\mathrm{C}$, using thickness reductions per pass of $25 \%, 50 \%, 66 \%$, and $80 \%$, were performed. It was found that both the ultimate grain size achieved, as well as the degree of bonding, depend on the rolling temperature and on the thickness reduction per pass. Higher temperatures and higher reductions promote a larger degree of bonding. Increasing strain also favors the formation of a more homogeneous microstructure. The smallest grain sizes were obtained at the lowest rolling temperature.
\end{abstract}

Keywords: Magnesium; Severe plastic deformation; Accumulative roll bonding

\section{Introduction}

Severe plastic deformation (SPD) techniques have emerged in the last decade as effective methods for the production of bulk metallic materials with very fine grain sizes $[1,2]$. These methodologies may additionally become important tools for grain boundary engineering once the links between the processing parameters and the resulting microstructural features are better established. A rather large body of research has been published on the efficacy of techniques such as equal channel angular pressing (ECAP) and high-pressure torsion (HPT) for grain refinement of a number of metallic materials [3-5]. The former, consisting on passing a billet through an angular die repeated times, allows producing ultrafine grain sizes $(d \approx 200-300 \mathrm{~nm})$. The use of HPT, where a diskshaped sample is simultaneously pressed (with pressures of the order of GPa) and sheared by a plunger, has led to the production of genuine nanostructures $(d<100 \mathrm{~nm})$. In recent years, a number of alternative SPD technologies have been developed, including accumulative roll bonding (ARB) [6], cyclic extrusion, cyclic bending, constrained grooved pressing, and others [7]. The processing-microstructure relationships corresponding to these techniques are still only scarcely known. ARB, in particular, has potential to be adopted by industry to produce fine-grained materials in the form of large sheets, due to its feasibility as a continuous process. This SPD method has been used to fabricate ultrafine-grained microstructures in $\mathrm{Al}$ and $\mathrm{Mg}$ alloys [8,9]. However, the information available in the literature regarding the goodness of the bonding achieved as well as the effectiveness of ARB for grain refinement is still very limited.

The need of a cost-effective processing route capable of producing Mg alloys with very fine grain sizes is currently one of the driving forces for research into this kind of materials. With a density only slightly higher than that of some polymers $\left(1.7 \mathrm{~g} / \mathrm{cm}^{3}\right), \mathrm{Mg}$ alloys are the lightest structural material [10]. Despite this exceptional advantage, which makes these materials very attractive for the transportation industry, their applications are rather limited due to relatively low absolute strength and ductility values. Reducing the grain size until the ultrafine $(100 \mathrm{~nm}<d<500 \mathrm{~nm})$ or the nanoscales would thus make these alloys competitive in terms of strength with respect to other 
heavier materials, such as aluminum alloys. Additionally, small grain sizes often allow superplasticity at the appropriate temperatures and strain rates. Thus, fine-grained $\mathrm{Mg}$ alloys would be susceptible to be formed into complex parts in one single operation by superplastic forming. In this paper, the efficiency of ARB to produce a fine-grained microstructure in the $\mathrm{Mg}-\mathrm{Al} \mathrm{AZ61}$ alloy is investigated.

\begin{tabular}{|c|c|c|c|c|c|}
\hline Sample & No. of slabs in the stack & Reduction (\%) & Final thickness (mm) & Temperature $\left({ }^{\circ} \mathrm{C}\right)$ & Bonding successful \\
\hline A & 2 & 25 & 1.5 & 300 and 400 & No \\
\hline B & 2 & 50 & 1 & 300 and 400 & No \\
\hline $\mathrm{C}$ & 5 & 66 & 1 & 300 and 400 & Yes \\
\hline $\mathrm{D}$ & 5 & 80 & 1 & 300 and 400 & Yes \\
\hline
\end{tabular}

Table 1 Details of the different ARB routes performed

\section{Experimental procedure}

The AZ61 alloy studied was received in the form of a rolled and, subsequently, annealed sheet. The initial microstructure is formed by equiaxed grains with an average size of $54 j \mathrm{~m}$, and a strong basal texture. The main alloying additions are $\mathrm{Al}(6 \%)$ and $\mathrm{Zn}(1 \%)$.

The original sheet of the AZ61 alloy, with a thickness of $3 \mathrm{~mm}$, was initially cut in several $3 \mathrm{~cm} \times$ $10 \mathrm{~cm}$ rectangular pieces, which were each rolled using a first pass of $30 \%$ reduction (i.e., the thickness was reduced to $2 \mathrm{~mm}$ ) and a second pass of $50 \%$ reduction (after which the thickness was reduced to $1 \mathrm{~mm}$ ). The first low-reduction pass is needed in order to prepare the microstructure for further passes with large thickness reductions per pass [11]. The microstructures obtained after this first rolling stage will be called ARB0. Next, several stacks of two, three, and five rolled slabs were prepared, reheated, and rolled again using one pass of $25 \%, 50 \%, 66 \%$, and $80 \%$ reduction, respectively. The microstructures after this second rolling stage will be termed ARB1. The details of each ARB1 route are summarized in Table 1. It was aimed that the sheets weld during rolling and, thus, one single sheet is obtained for each stack. However, as indicated in Table 1, only the samples with reductions higher than 50\% were bonded successfully. Lower reductions were not sufficient to bond the slabs and delamination occurred while cutting the samples. Thus, this study will focus on the samples that were rolled using reductions of $66 \%$ and $80 \%$, where bonding took place to some extent. Rolling was performed both at $400^{\circ} \mathrm{C}$ and $300^{\circ} \mathrm{C}$ in a Carl Wezer rolling machine, furnished with two $13 \mathrm{~cm}$-diameter rolls that rotate at $52 \mathrm{rpm}$. Before each pass, the samples were heated at the rolling temperature for $5 \mathrm{~min}$. The surface of the slabs was ground using a 400 grit SiC paper before stacking for ARB. The rolls were neither lubricated nor heated. In order to estimate the degree of bonding as a function of the rolling reduction as well as of the rolling temperature, the ARB1 samples were further annealed at $400 \mathrm{C}$ during $30 \mathrm{~min}$ and the interface between different layers was examined. Microstructural observation was performed by optical microscopy.

\section{Results and discussion}

Fig. 1 shows the microstructural evolution of the AZ61 alloy upon accumulative roll bonding at 400

C. After the initial two passes of, respectively, 30\% and 50\% reduction (ARB0)(Fig. 1a and b), a bimodal microstructure appears, which is formed by regions populated by large grains as well as a relatively large volume fraction of small, recrystallized submicrometer grains, that are not resolvable via optical microscopy. The latter are mainly grouped forming bands at $45^{\circ}$ with the rolling direction. In a previous paper [11], on large strain hot rolling of this AZ61 alloy, it was concluded that this heterogeneous microstructure is a consequence of the operation of several dynamic recrystallization mechanisms. Given the initial strong basal texture, most of the grains are 
not favorably oriented for slip. Thus, during the first pass with $30 \%$ reduction, rather large stresses accumulate in the areas close to grain boundaries. This gives rise to a localized motion of dislocations, resulting in the rotation of the "mantle" regions to orientations that are more prone to slip under the rolling conditions imposed. This process is termed rotational recrystallization (RRX) [12]. The microstructure would then be ready to accommodate further rolling reductions (in this case, a second pass with $50 \%$ reduction), with deformation taking place mainly in the "ductile zones" (or regions formed by bands of small grains rotated away from the original grains with basal orientations). The larger grains would be the remains of the original grains. After an additional ARB pass (ARB1) with 66\% thickness reduction (Fig. 1c and d), a similar microstructure develops, albeit with a smaller fraction of large grains. Again, this could be rationalized taking into account that continuing RRX would contribute to increase the fraction of small grains at the expense of the large ones. Deformation bands at $45^{\circ}$ angles with respect to the rolling direction are here also clearly visible. Fig. 1d illustrates the interface between two slabs after ARB with a thickness reduction of $66 \%$. It can be noticed that bonding takes place mainly on the areas occupied by the shear bands, where the interface becomes almost invisible. This again reflects the fact that most of the deformation is accommodated in these areas. Finally, if a reduction of $80 \%$ is applied during ARB (Fig. 1e and f), the microstructure becomes quite homogeneous. This may be attributed to the saturation of the RRX mechanism. The final grain size achieved, about $3 j \mathrm{~m}$, is larger than that obtained within the deformation bands apparent with smaller ARB reductions. The larger amount of strain energy accumulated on the material as a consequence of the higher thickness reduction per pass might constitute a driving force for grain growth.

Fig. 2 shows the evolution of the microstructure after ARB at $300 \mathrm{C}$. In general terms, the same trends can be observed as those described above for the samples ARBed at $400^{\circ} \mathrm{C}$. After an ARB pass with $66 \%$ reduction (Fig. $2 \mathrm{a}$ and $\mathrm{b}$ ) a bimodal grain size distribution is still present. It must be noted that the recrystallized grains are now smaller than those obtained at lower temperatures. This may be due to the slowest rate of diffusion at this lower temperature. Upon higher reductions (Fig. $2 \mathrm{c}$ and $\mathrm{d}$ ), an homogeneous microstructure develops, again with a smaller grain size (about 1-2 $\mu \mathrm{m}$ ) than its $4000^{\circ} \mathrm{C}$ counterpart.

In order to investigate the degree of bonding, the ARBed samples were subsequently annealed at $400 \mathrm{C}$ for $30 \mathrm{~min}$. Fig. 3 shows the interfaces corresponding to the samples that were roll bonded at $400 \mathrm{C}$ with $66 \%$ thickness reduction (Fig. 3a), at $400 \mathrm{C}$ with $80 \%$ reduction (Fig. 3b), and at 300 $\mathrm{C}$ with $80 \%$ reduction (Fig. $3 \mathrm{c}$ ). It is considered that bonding has taken place successfully at a specific region when the interface becomes invisible. The waviness of the interface reveals regions where deformation bands intersected, causing, as shown in Fig. 1d, successful bonding. It can be seen that the degree of bonding is better at higher temperatures and with larger rolling reductions. In particular, in the samples that were rolled at $400{ }^{\circ} \mathrm{C}$ using an ARB reduction of $80 \%$, the fraction of bonded interface is approximately 50\%. Therefore, the present results indicate that, in spite of the fact that a dramatic grain size refinement can be obtained in the $\mathrm{Mg}-\mathrm{Al}$ alloy via $\mathrm{ARB}$, the bonding degree achieved is not very good. However, recent investigations on diffusion bonding of a $\mathrm{Mg}$ AZ31 alloy have shown that bonding degrees of about $50 \%$ are sufficient to avoid worsening of the mechanical properties [13]. Further work is currently being performed in order to investigate the mechanical properties of the ARBed samples.

\section{Summary}

The effectiveness of accumulative roll bonding for the fabrication of very fine microstructures of an $\mathrm{AZ61} \mathrm{Mg}-\mathrm{Al}$ alloy was investigated. The following conclusions can be drawn from this study:

1. ARB does produce a dramatic grain size refinement. Grain sizes on the submicron range can be obtained after only 1 ARB pass with $66 \%$ thickness reductions. Lower temperatures favor the 
appearance of smaller grain sizes. Larger reductions per pass result in increasingly homogeneous microstructures.

2. The degree of bonding achieved between the different roll bonded layers only amounted to about $50 \%$ under the most favorable processing conditions.

\section{Acknowledgements}

The authors acknowledge financial support form CICYT (Spain) under program MAT 2000-1313. J.A.V. is thankful to the Spanish Ministry of Education and Science for a Ramón y Cajal contract.

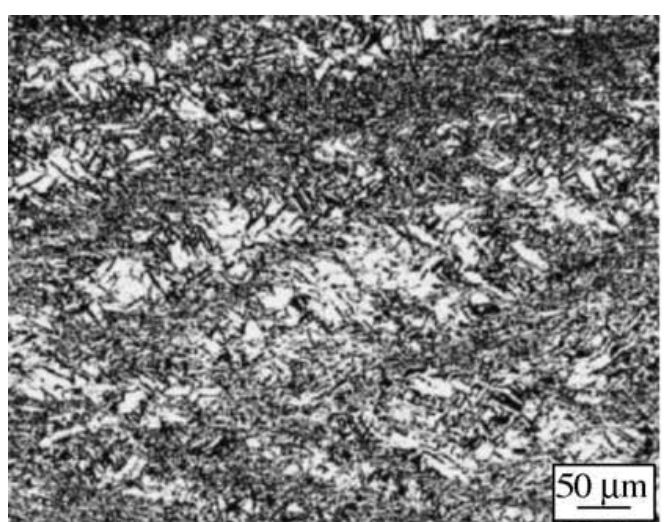

(a)

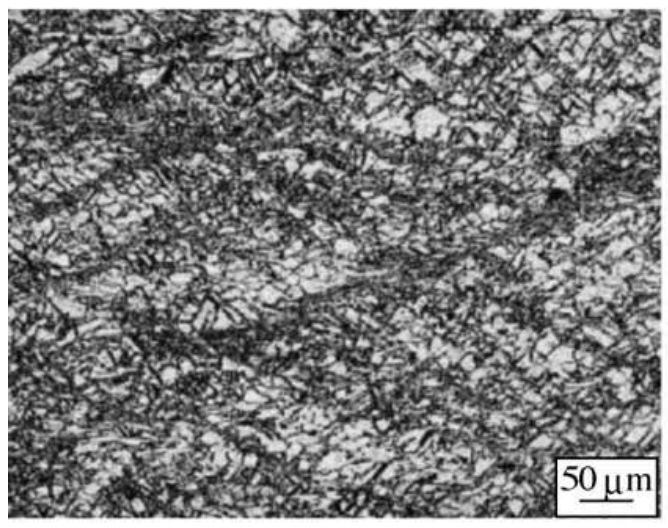

(c)

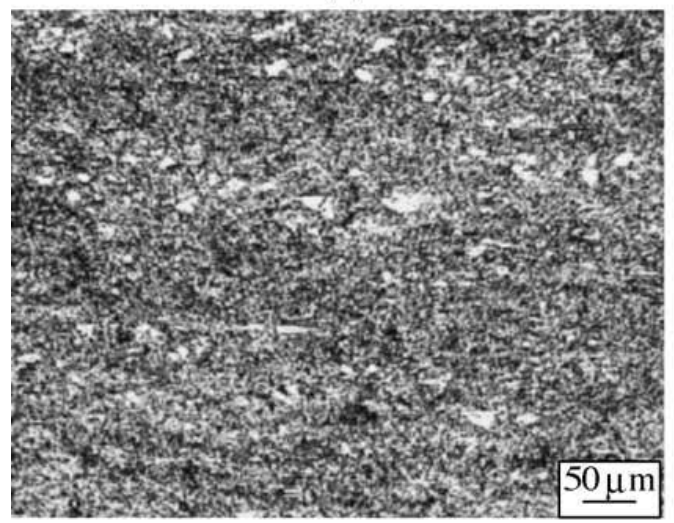

(e)

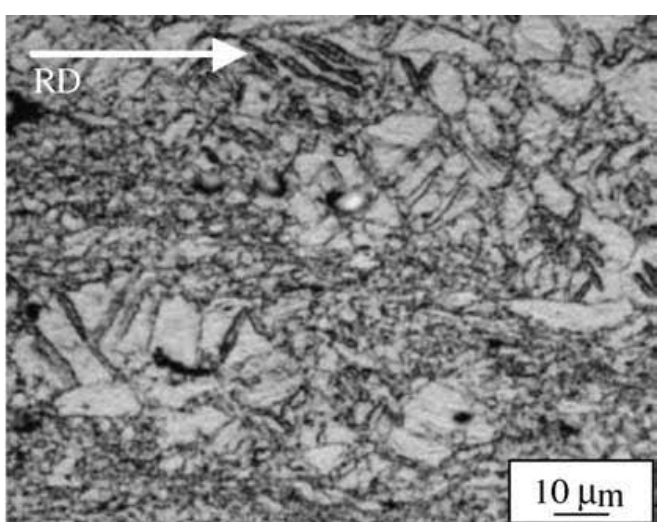

(b)

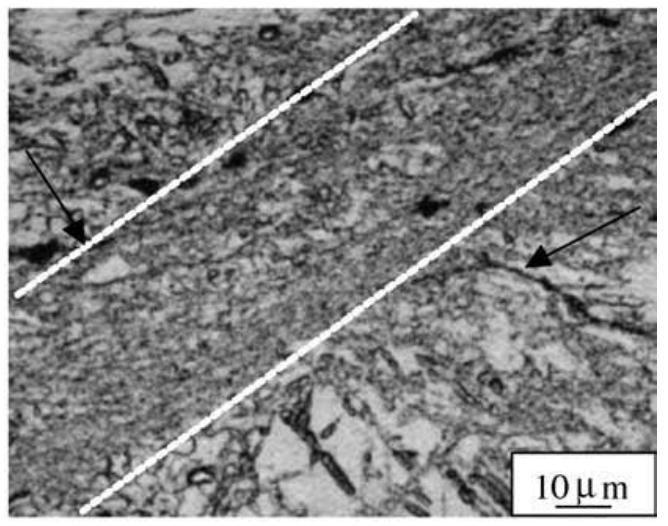

(d)

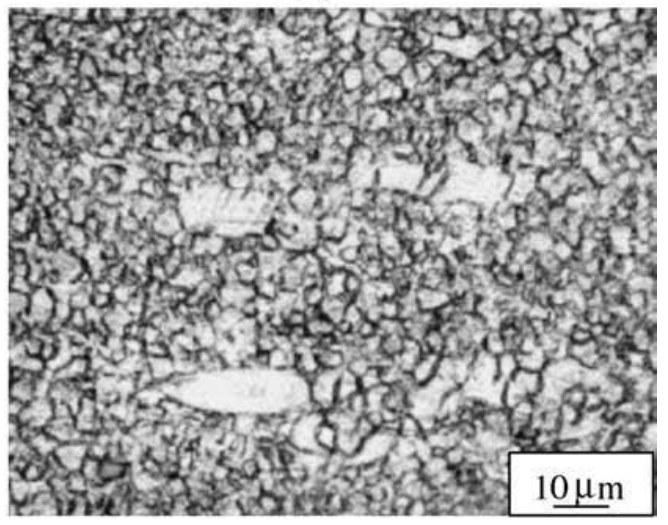

(f)

Fig. 1. Microstructural evolution of the AZ61 alloy after accumulative roll bonding at $400 \mathrm{C}$. (a and b) ARB0: 1 pass with $30 \%$ reduction and a second pass with 50\% reduction; (c and d) ARB1: a third pass with $66 \%$ thickness reduction; (e and f) a third pass with $80 \%$ reduction. The rolling direction is the horizontal. 


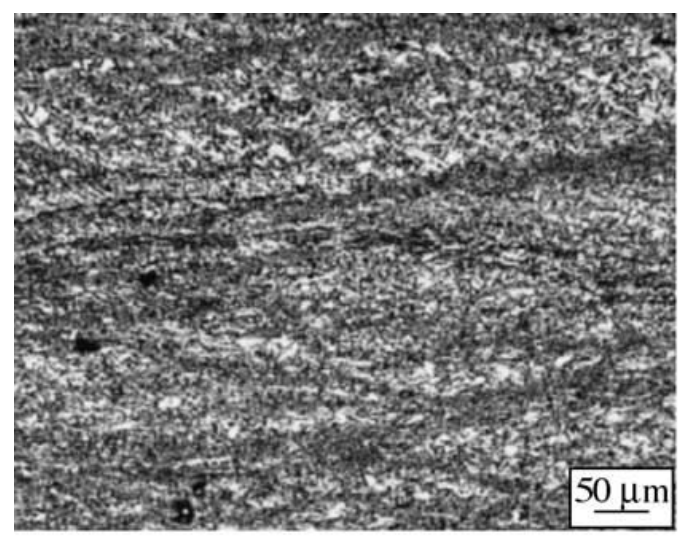

(a)

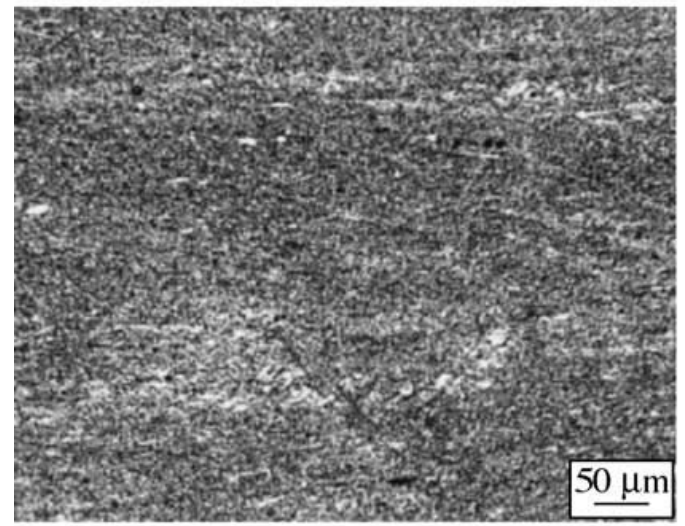

(c)

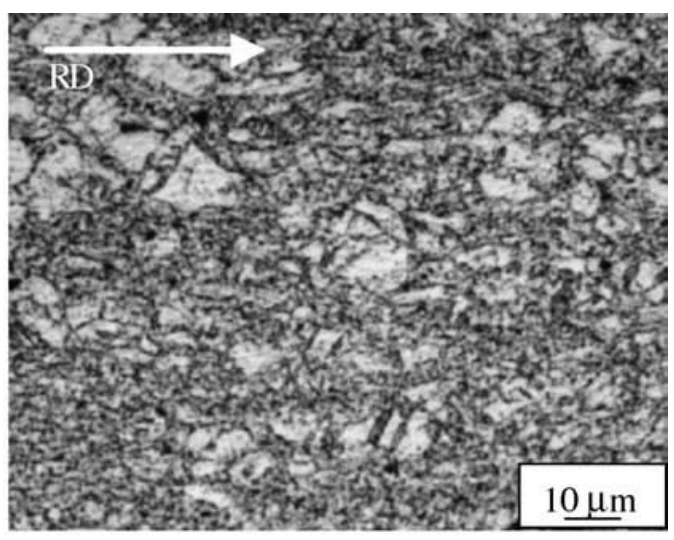

(b)

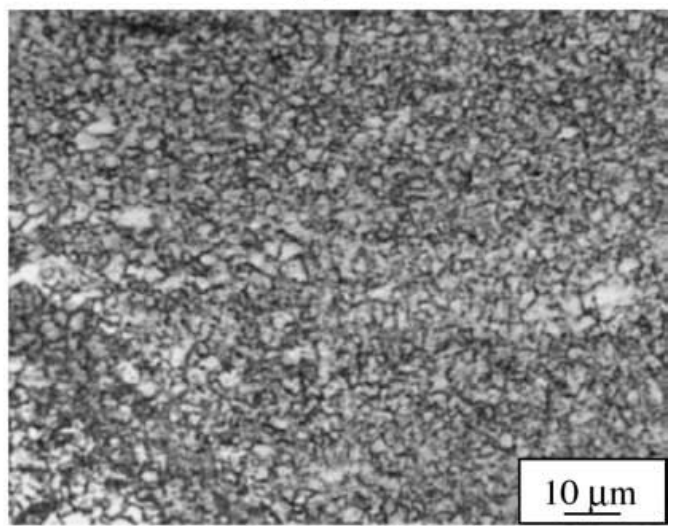

(d)

Fig. 2. Microstructural evolution of the AZ61 alloy after accumulative roll bonding at $300^{\circ} \mathrm{C}$. (a and b) ARB1: a third pass with $66 \%$ thickness reduction; (c and d) a third pass with $80 \%$ reduction. The rolling direction is the horizontal. 


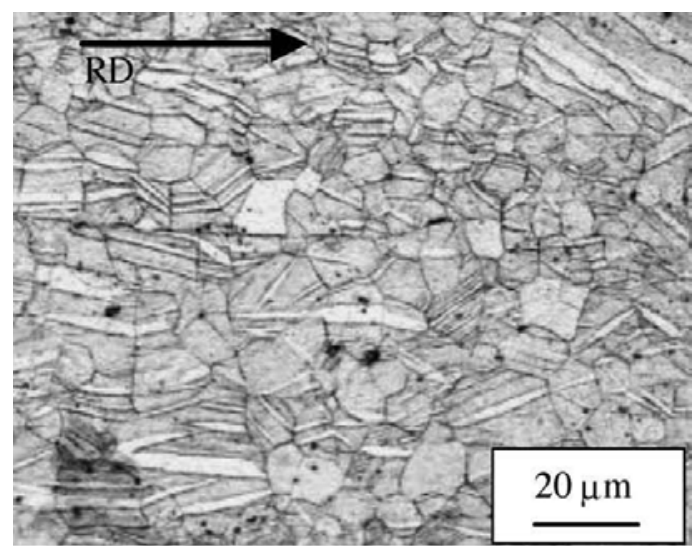

(a)

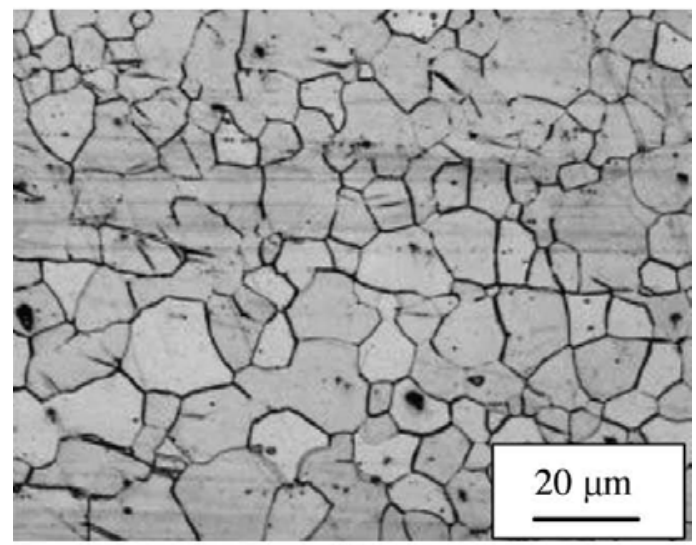

(b)

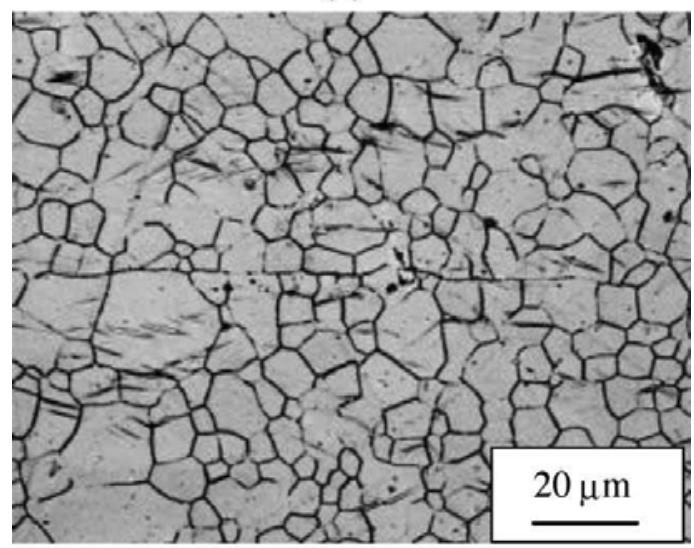

(c)

Fig. 3. Optical micrographs showing the interface between two adjacent layers, after accumulative roll bonding under different conditions. (a) $400{ }^{\circ} \mathrm{C}$ with $66 \%$ thickness reduction; (b) $400 \circ \mathrm{C}$ with $80 \%$ reduction; (c) $300 \circ \mathrm{C}$ with $80 \%$ reduction. The rolling direction is the horizontal. 


\section{References}

[1] R.Z. Valiev, Nat. Mater. 3 (2004) 511-516.

[2] R.Z. Valiev, R.K. Islamgaliev, I.V. Alexandrov, Prog. Mater. Sci. 45 (2000) 103-189.

[3] M. Furukawa, Z. Horita, M. Nemoto, T.G. Langdon, Mater. Sci. Eng. 324 (2002) 82-89.

[4] Y. Iwahashi, Z. Horita, M. Nemoto, T.G. Langdon, Acta mater. 46 (1998) 3317-3331.

[5] A.P. Zhilyaev, G.V. Nurislamova, B.K. Kim, M.D. Baró, J.A. Szpunar, T.G. Langdon, Acta Mater. 51 (2003) 753-765.

[6] N. Tsuji, Y. Saito, S.H. Lee, Y. Minamino, Adv. Eng. Mater. 5 (2003) 338-344.

[7] M.J. Zehetbauer, R.Z. Valiev (Eds.), Proceedings of the Conference on Nanomaterials by Severe Plastic Deformation (NANO-SPD2), Wiley-VCH Verlag, Vienna, Austria, 2002.

[8] H.W. Hoppel, J. May, M. Goken, Adv. Eng. Mater. 6 (2004) 219- 222.

[9] M.T. Pérez-Prado, J.A. del Valle, O.A. Ruano, Scripta Mater. 51 (2004) 1093-1097.

[10] B.L. Mordike, T. Ebert, Mater. Sci. Eng. A 302 (2001) 37.

[11] J.A. Del Valle, M.T. Pérez-Prado, O.A. Ruano, Mater. Sci. Eng. 355 (2003) 68-78.

[12] S.E. Ion, F.J. Humphreys, S.H. White, Acta Metal. 30 (1982) 1909-1919.

[13] H. Somekawa, H. Watanabe, T. Mukai, K. Higashi, Scripta Mater. 48 (2003) 1249-1254. 